\title{
Minireview \\ First-line endocrine treatment of breast cancer: aromatase inhibitor or antioestrogen?
}

\author{
Z-W Wong' and MJ Ellis*,2 \\ 'National Cancer Centre, Singapore; 'Breast Cancer Program, Washington University, 660 South Euelid, Campus Box 8056, St Louis, MO 63I I0, USA
}

Until recently, endocrine therapy for breast cancer was relatively simple. If the tumour expressed hormone receptors, regardless of stage and age, tamoxifen was indicated. While this largely remains the case for premenopausal women, clinical trials in postmenopausal women have broadened our choice to include one of three selective aromatase inhibitors (Als), the nonsteroidal agents anastrozole or letrozole and the steroidal agent exemestane. Comparative data concerning the efficacy, toxicity, tolerability and cost of Al vs tamoxifen continues to evolve with over 40000 women slated to be involved in clinical trials. Currently, tamoxifen remains an appropriate choice for adjuvant treatment, and will remain so unless a clear survival advantage emerges for adjuvant $\mathrm{Al}$ therapy. However, anastrozole is widely seen as a useful alternative, with particular merit for patients prone to the development of serious tamoxifen side effects. For endocrine therapy naïve advanced disease, several trials have provided evidence that a nonsteroidal Al has replaced tamoxifen as optimal treatment. In the neoadjuvant setting, letrozole was also more effective than tamoxifen, both in terms of response rates and the incidence of breast-conserving surgery, and so Al therefore also dominates this evolving indication. The ongoing adjuvant clinical trials ask all the relevant questions regarding tamoxifen and $\mathrm{Al}$ in combination, sequence and duration, except for 5 years of an $\mathrm{Al}$ vs a longer period. For both the advanced and early-stage disease, resistance remains the key obstacle to overcome, and trials that combine endocrine agents with signal transduction inhibitors such as HERI and HER2 kinase inhibitors, farnesyl transferase inhibitors, mTOR inhibitors as well as COX2 inhibitors are being developed in a concerted attempt to address this problem.

British Journal of Cancer (2004) 90, 20 -25. doi:I0.1038/sj.bjc.660I508 www.bjcancer.com

(c) 2004 Cancer Research UK

Keywords: endocrine; breast cancer; aromatase inhibitor; antioestrogen

Formulating a view on the relative merits of aromatase inhibitors (AIs) and tamoxifen requires an examination of the available evidence regarding four major issues - efficacy, toxicity, tolerability/quality of life and cost. Each of these factors must be considered in the context of three major indications for endocrine treatment - neoadjuvant, adjuvant and advanced disease. While prevention is a fourth potential indication, there are no data yet from prevention trials to discuss. However, the arimidex, tamoxifen alone or in combination (ATAC) trial supports the hypothesis that AIs have chemopreventive properties, and clinical trials are now ongoing. For this review, 'antioestrogen' is synonymous with tamoxifen, because the two other approved antioestrogens either have no comparative data with AIs (toremifene) or published comparisons with AIs were not conducted in the first-line setting (fulvestrant).

\section{What is first-line endocrine treatment for breast cancer?}

First-line treatment for breast cancer is the easiest to define in terms of a new diagnosis, whether a new primary or initial systemic relapse. However, these events do not necessarily equate to first-line endocrine therapy because the patient may have already been exposed to raloxifene for osteoporosis or tamoxifen for chemoprevention. There are unfortunately only limited data to

*Correspondence: Dr MJ Ellis; E-mail: mellis@im.wustl.edu

Received 14 August 2003; accepted 3I October 2003 guide the clinical management of these patients. The recommendation to use an adjuvant AI in selective oestrogen receptor modulation (SERM)-exposed patients (Winer et al, 2002) stems from advanced disease trials in which patients either relapsing on or after tamoxifen therapy still have a reasonable chance of responding to AIs (Smith and Dowsett, 2003). Similarly, a patient with newly diagnosed hormone receptor-positive advanced disease is highly likely to have already been treated with adjuvant tamoxifen. If the relapse occurred on tamoxifen or within 6 months to 1 year of stopping tamoxifen, then the patient is considered to be in a 'second-line endocrine therapy' category, and the standard recommendation is an AI (Smith and Dowsett, 2003). Patients who relapse after an interval of more than 1 year are traditionally considered 'first-line' endocrine therapy candidates, as the standard of care was to reintroduce tamoxifen therapy. However, a recent large study demonstrated that this is a relatively ineffective strategy, with an odds ratio favouring letrozole treatment approaching 4 in this subgroup (Mouridsen et al, 2003). Perhaps, any patient who has completed a course of adjuvant tamoxifen could really be considered to be a candidate for second-line endocrine therapy upon relapse, regardless of how long ago the exposure to tamoxifen was.

\section{Antioestrogens and AIs have distinct mechanisms of action}

Tamoxifen (antioestrogen) and aromatase inhibition (oestrogen deprivation) are distinct approaches to oestrogen-dependent 
breast cancer and efficacy, tolerability and toxicity differences stem from these pharmacological fundamentals (Smith and Dowsett, 2003). Unlike tamoxifen, AIs do not exhibit intrinsic hormonal properties but affect oestrogen receptor (ER) function indirectly by blocking the conversion of adrenal androgens to oestrogen in the peripheral (i.e. nonovarian) tissues of postmenopausal women, including the breast itself (Miller, 1991). When deprived of oestrogens, ERs cannot bind to DNA, and are therefore incapable of direct involvement in signalling. As a consequence, the side effects of AIs stem from oestrogen deprivation - for example, bone loss and atrophic vaginitis. In contrast, tamoxifen has an intrinsic endocrine action by binding to ERs with high affinity and activating ER dimerisation and DNA binding. Tamoxifen-bound ER has altered gene-regulatory properties referred to as SERM. In several normal tissues, tamoxifen-bound ER is active and promotes, for example, bone mineralisation and endometrial proliferation. In these instances, tamoxifen is acting as an 'oestrogen mimic' or receptor agonist. As a consequence, the serious side effects of tamoxifen are remarkably similar to oestrogen replacement therapy (ERT) - venous thrombosis, pulmonary embolus, stroke and endometrial cancer (ATAC, 2002). Like ERT, maintenance of bone mineral density is an advantage of tamoxifen. These agonist effects may, however, limit efficacy. Aromatase inhibitors do not interact with ER; so potential resistance mechanisms related to SERM agonist effects on tumour cells are avoided. Preclinical models with MCF7 xenografts engineered to overexpress aromatase (Brodie et al, 2003), as well as models of tamoxifen-dependent tumour growth (Gottardis and Jordan, 1988), support this explanation for the therapeutic advantage of AIs.

\section{First-line therapy for advanced disease}

This discussion will focus on anastrozole, letrozole and exemestane. Fadrozole, a second-generation nonsteroidal AI, has been shown to be equivalent to tamoxifen (Thurlimann et al, 1996) but inferior to letrozole (Tominaga et al, 2003) in advanced breast cancer, and will not be discussed further, as drug approval is restricted to Japan.

\section{Anastrozole}

Anastrozole has been compared with tamoxifen as first-line endocrine therapy in more than 1000 postmenopausal metastatic breast cancer patients with either positive or unknown hormone receptor status in two randomised double-blind trials. The study from Europe (Bonneterre et al, 2000) showed similar time to progression (TTP) and clinical benefit rates (defined as $\mathrm{CR}+\mathrm{PR}+$ disease stabilisation of $>24$ weeks) in the anastrozole and tamoxifen arms of the study (8.2 vs 8.3 months and 56.2 and $55.5 \%$, respectively). In the North American study (Nabholtz et al, 2000 ), anastrozole was significantly superior to tamoxifen for both TTP and clinical benefit rates (11.1 vs 5.6 months, $P=0.005$ and 59.1 vs $45.6 \%, P=0.0098$, respectively). It is important to note that there was a marked difference in the prevalence of known receptor-positive patients between the two studies (45 and $89 \%$, respectively), potentially accounting for the differences observed. The combined data analysis from the two studies showed anastrozole to be equivalent to tamoxifen in TTP at a median follow-up of 18.2 months (Bonneterre et al, 2001), but, in a retrospective subgroup analysis, anastrozole was superior to tamoxifen in the subgroup with known receptor-positive tumours with respect to TTP (10.7 vs 6.4 months). In addition, although anastrozole had similar objective response rates (29.0 vs $27.1 \%)$, the clinical benefit rates were higher (57.1 vs 52.0\%). It is therefore reasonable to conclude that anastrozole is superior in terms of TTP for patients with receptor-positive tumours. The controversy over the interpretation of unplanned retrospective analyses used by these investigators underscores the inappropriateness of including patients with unknown receptor status in these studies. To avoid this problem, patients without hormone receptor data are likely to be excluded from future endocrine therapy trials.

\section{Letrozole}

Letrozole was compared with tamoxifen in a randomised trial of 907 patients, whose tumours were receptor positive or unknown (Mouridsen et al, 2001). Recurrence during adjuvant antioestrogen therapy or within the following 12 months or prior endocrine therapy for advanced disease precluded enrollment, and only one prior chemotherapy regimen for metastatic disease was allowed. Letrozole treatment was found to be superior to tamoxifen, with a median TTP of 41 weeks vs 26 weeks. The median time to treatment failure, overall response rate and clinical benefit rate were significantly better in favour of letrozole (40 vs 25 weeks; 30 vs $20 \%, P=0.0006$ and 49 vs $38 \%, P=0.001)$. At a recent update after a median of 32 months of follow-up, the superiority of letrozole over tamoxifen in the TTP (median, 9.4 vs 6.0 months, respectively; $P<0.0001$ ), time to treatment failure (median, 9 vs 5.7 months, respectively; $P<0.0001$ ), overall objective response rate (32 vs $21 \%$, respectively; $P=0.0002$ ) and overall clinical benefit were confirmed (Mouridsen et al, 2003). Interestingly, the total duration of endocrine therapy ('time to chemotherapy') was significantly longer for first-line letrozole than for first-line tamoxifen (median, 16 months $v s 9$ months, $P=0.005)$. Similarly, the time to worsening of Karnofsky performance score was also significantly delayed with letrozole compared with tamoxifen, underscoring the palliative benefits of a first-line AI approach.

\section{Exemestane}

Exemestane has been compared with tamoxifen in 117 previously untreated breast cancers with either positive or unknown hormone receptors in a randomised phase 2 EORTC study (Dirix et al, 2001). The overall response rate was better for exemestane than tamoxifen (44.6 vs 14.3\%). Time to progression has not been analysed, as this is the primary end point of a Phase 3 extension of this ongoing study.

\section{Interpretation of the advanced disease data}

The letrozole experience, by virtue of the consistent findings and highly significant effects on the TTP and response rate, provided the best evidence for the advantage of first-line AI treatment. These advantages were independent of a number of baseline covariates, including the site of disease, prior use of tamoxifen and known or unknown hormone receptor status (Mouridsen et al, 2003). The overall survival data from this trial have raised some interesting issues regarding the sequencing of tamoxifen and letrozole. Whereas women on letrozole had a clear trend towards improved survival during the first 2 years, this survival benefit was 'lost' after further follow-up (median survival 34 months with letrozole $v s 30$ months for tamoxifen). As a result, several parametric tests were not significant when applied to the data $(P=0.53$ log rank, $P=0.079$ Wilcoxon). However, the nonparametric KolmogorovSmirnov-type test did indicate that the two survival curves were significantly different in favour of letrozole between 6 and 20 months $(P=0.003)$. An obvious explanation for the apparently 'temporary' survival advantage for first-line letrozole is that crossover to letrozole also improved survival as second-line treatment on the tamoxifen arm. The alternative hypothesis is that cross-over to tamoxifen decreased the survival rate of patients who received letrozole first. This possibility is not completely far-fetched. Prolonged oestrogen deprivation causes oestrogen hypersensitivity 
(Santen et al, 2003), which might also prime a cell to perceive tamoxifen as an agonist. Clearly, trials that investigate the endocrine management of patients with AI-resistant advanced disease are of major priority. The options now include tamoxifen, fulvestrant (Howell, 2000) or switching from a nonsteroidal AI to exemestane (Lonning et al, 2000). The data available on these strategies are limited, but the response rates are generally less than $10 \%$. In fact, perhaps the most active approach may be pharmacological doses of oestrogen (Ingle, 2002), which would concur with the apoptotic response of long-term oestrogen deprived cells to the reintroduction of oestrogen (Song et al, 2001).

From the view of current practice, the higher response rate and lower incidence of early progression when treating with letrozole first translate into a quality of life benefit and staves off, the moment palliative chemotherapy becomes necessary. This efficacy distinction between AIs and tamoxifen is perhaps most important for patients with disease involving vital organs, where disease progression is most likely to trigger the use of palliative chemotherapy. Aromatase inhibitors are quite active against visceral disease and superior to tamoxifen in this regard (Mouridsen et al, 2003). For patients with low volume disease and low symptom burden, the order of treatment is arguably less critical, because several endocrine agents are likely to be used in the sequence, regardless of treatment response.

\section{Aromatase inhibitor $v s$ tamoxifen as adjuvant therapy for breast cancer}

Around 40000 patients are either scheduled to enroll or have enrolled in adjuvant studies involving AIs, but the only study that has been reported so far is the ATAC trial (ATAC, 2002). In all, 9366 patients were recruited, of whom 3125 were randomly assigned anastrozole, 3116 tamoxifen and 3125 a combination of both. A total of 7839 patients (84\%) were known to be receptorpositive. With a median follow-up of 33.3 months, the disease-free survivals (defined as freedom from local recurrence, systemic recurrence, contralateral breast cancer or death as first event) at 3 years were $89.4 \%$ on anastrozole and $87.4 \%$ on tamoxifen (hazard ratio $0.83(95 \%$ CI $0.71-0.96), P=0.013)$. Results with the combination were not significantly different from those with tamoxifen alone $(87.2 \%, 1.02(0.89-1.18), P=0.8)$. Improvements in disease-free survival with anastrozole were only seen in the receptor-positive population. The incidence of contralateral breast cancer was also significantly lower with anastrozole than with tamoxifen (odds ratio $0.42(0.22-0.79), P=0.007)$. After 47 months of follow-up and 1373 events, the DFS estimates were 86.9 and $84.5 \%$ for anastrozole and tamoxifen, respectively (Buzdar, 2002). The actual events that make up these statistics are provided in Table 1 . The difference in DFS estimates was slightly greater in the hormone-receptor positive subgroup $(89.0 \mathrm{vs}$ $86.1 \%)$. These differences remain modest in absolute terms and

Table I Updated efficacy results of ATAC trial with a median follow-up of 47 months

\begin{tabular}{lccc}
\hline & $\begin{array}{c}\text { AN } \\
(\mathbf{n}=\mathbf{3} \mathbf{1 2 5})\end{array}$ & $\begin{array}{c}\text { TAM } \\
(\mathbf{n}=\mathbf{3} \mathbf{I} \mathbf{~ 1 6})\end{array}$ & $\begin{array}{c}\text { AN+TAM } \\
(\mathbf{n}=\mathbf{3} \mathbf{2 5})\end{array}$ \\
\hline Deaths before recurrence & 108 & 109 & 100 \\
First event & 413 & 472 & 488 \\
Locoregional & 84 & 101 & 107 \\
Distant & 195 & 222 & 246 \\
CL (invasive) & 20 & 35 & 30 \\
CL (DCIS) & 5 & 5 & 5 \\
\hline
\end{tabular}

$\mathrm{AN}=$ anastrozole; $\mathrm{TAM}=$ tamoxifen; $\mathrm{CL}=$ contralateral breast cancer; $\mathrm{DCIS}=$ ductal carcinoma in situ.

$\begin{array}{lll} & \text { Neurocognition? } & \downarrow \text { Relapse rate } \\ \downarrow \text { Osteoporosis risk } & \text { Sexual function? } & \downarrow \text { DVT } \\ \downarrow \text { Cost } & \text { Hyperlipidaemia? } & \downarrow \text { Stroke } \\ \downarrow \text { M/S syndrome } & \text { Cardiovascular disease? } & \downarrow \text { Endometrial CA } \\ & & \downarrow \text { Hot flushes }\end{array}$

Tamoxifen

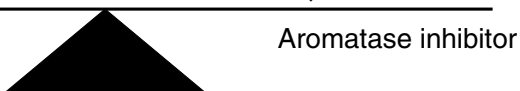

Figure I Comparison of toxicities of $\mathrm{Al}$ vs tamoxifen from the ATAC trial $(C A=$ cancer, $D V T=$ deep venous thrombosis, $M / S=$ musculoskeletal).

persistent divergence of the curves with further follow-up, as well as supportive data from other trials, will be very reassuring to patients embarking on anastrozole as adjuvant treatment. With each trial update, the risks and benefits will be weighed (Figure 1). Only when the efficacy data become stronger, particularly with respect to overall survival, or the differences in toxicity becomes greater, are we likely to see a change in the ASCO technical review on adjuvant AIs, which emphasises the strength of the tamoxifen experience and the preliminary nature of the ATAC trial data (Winer et al, 2002, 2003). This view was also endorsed by the recent St Gallen Consensus Panel, which also recommended that anastrozole be used only in postmenopausal women in whom tamoxifen is contraindicated, or is not tolerated (Goldhirsch et al, 2003).

\section{Neoadjuvant AI therapy}

The results of a randomised comparison of letrozole and tamoxifen as neoadjuvant therapy for postmenopausal women with Stage 2 and 3, hormone receptor-positive disease are noteworthy from a number of standpoints (Eiermann et al, 2001). Letrozole produced a higher clinical and radiological response rate than tamoxifen, and also the incidence of breast-conserving surgery was superior (all patients in the trial were considered ineligible for breastconserving surgery at baseline). This result therefore mirrors the conclusion from the ATAC trial that a third-generation AI is more effective than tamoxifen as treatment for primary breast cancer. If neoadjuvant and adjuvant endocrine outcomes continue to be concordant in this way, future novel endocrine strategies may well use the neoadjuvant setting to establish essential preliminary data to support a definitive large-scale adjuvant trial. Another noteworthy aspect of the study concerned the opportunity to conduct biomarker research to better understand the molecular basis for the therapeutic response to endocrine agents. For example, an analysis of trial outcomes according to HER1 (EGFR) and HER2 (ErbB2) status demonstrated that the difference in the effectiveness of letrozole and tamoxifen was particularly marked for tumours that coexpressed ER and HER1 and/or HER2 (Ellis et al, 2001). This finding has led to an effort to examine the outcome of the ATAC study according to HER2 expression status (Dowsett $\mathrm{M}$, personal communication). Further biomarker research has also shown that the cell cycle-related biomarker Ki67 is suppressed to a greater extent by letrozole than tamoxifen, regardless of HER1 and HER2 expression status. This would suggest that part of the superior efficacy associated with aromatase inhibition is related to a greater inhibition of tumour proliferation (Ellis et al, 2003). A significant obstacle to the routine adoption of neoadjuvant endocrine therapy is the absence of a large validation study in which the outcomes of patients who received neoadjuvant AIs are directly compared with a group treated conventionally (either with neoadjuvant chemotherapy or immediate surgery). 
Conducting a trial of this nature is a priority, given the potential of research in this clinical context, as well as the inherent advantages from a wider acceptance of a low-toxicity approach to neoadjuvant treatment for older patients (Wong and Ellis, 2003).

\section{Toxicity and tolerability}

Differences in the side effect profile between tamoxifen and anastrozole are marked, and arguably more likely to influence the current prescribing practice than differences in efficacy. There is no difference between anastrozole and tamoxifen in terms of cataracts, ischaemic cardiovascular events, fatigue or asthenia, mood disturbances and nausea and vomiting. However, anastrozole was associated with fewer endometrial cancers, vaginal bleeding and discharge, cerebrovascular events, venous thromboembolic events and hot flushes. Tamoxifen caused fewer musculoskeletal disorders and fractures. These data have led the ASCO technical panel and the St Gallen Consensus panel to emphasise that anastrozole might have an important role for those at particular risk for severe tamoxifen side effects. On the other hand, anastrozole should be prescribed with caution in patients with osteopenia/osteoporosis. The increase in fracture risk associated with anastrozole was evident even at the first analysis, suggesting that the decline in bone strength may occur very rapidly in some patients, perhaps even before major changes in bone mineral density are detected. Arguably, all patients on adjuvant AI therapy should receive vitamin $\mathrm{D}$ and calcium supplements, be encouraged to exercise, and those with evidence for bone loss at baseline should also receive an oral bisphosphonate, until practice guidelines are established. The ASCO technical review and the St Gallen Consensus Panel continue to emphasise the lack of safety data regarding long-term oestrogen deprivation. For example, AIs have been reported to alter cholesterol and lipoprotein metabolism with potentially deleterious effects on cardiovascular health (Elisaf et al, 2001). There are also concerns about the effects of long-term oestrogen deprivation on memory and risk for dementia. Regions of the brain such as the hippocampus and amygdala involved in learning and memory are rich in ER, as oestrogen regulates synapse formation and induces choline transferase and acetylcholinesterase, both critical to memory function (McEwen et al, 1997). While tamoxifen has been implicated in decline in cognitive function (Paganini-Hill and Clark, 2000), these data do not come from double-blind randomised placebo-controlled trials, and so the issue remains controversial. The positive influence of oestrogen on the general health, vitality, mental health, depressive symptoms, or sexual satisfaction has recently been seriously questioned (Rossouw et al, 2002; Hays et al, 2003), and so, while these issues need careful study, the potential of AIs to be unduly toxic in the long run should not be overstated.

\section{Quality of life}

For metastatic breast cancer, balancing the toxicity-to-benefit ratio of any treatment is vital in maintaining the quality of life in otherwise incurable patients with a limited lifespan. In more than 900 patients enrolled in a multi-centre trial evaluating the efficacy of letrozole compared to tamoxifen as first-line therapy in metastatic breast cancer, letrozole offered a significantly longer quality-adjusted survival than tamoxifen (mean duration for TWiST or time without disease progression or toxicity was 10.1 months compared to 7.6 months for tamoxifen, $P=0.0004$ ) (Irish et al, 2002). Some have suggested that letrozole may be superior to anastrozole in terms of gastrointestinal side effects, nausea and hot flushes (Makris et al, 2002).

A European study that evaluated more than 500 women with early breast cancer after $2-3$ years of adjuvant tamoxifen found that the adverse effects of tamoxifen therapy on quality of life may be under-reported (Coombes et al, 2003). Using the FACT-ES (Functional Assessment of Cancer Therapy or FACT-B, plus ES, an 18-item five-point endocrine subscale), eight symptoms that were most problematic for $>10 \%$ of the patients included: hot flushes, night sweats, vaginal dryness, loss of interest in sex, weight gain, bloatedness, breast sensitivity and mood swings (Fallowfield et al, 1999). However, results from the NSABP-P1 study showed that there was no difference between tamoxifen and the placebo arms with regard to depression, overall physical or mental quality of life and weight gain, though those on the tamoxifen arm have more vasomotor (hot flushes) and gynecological symptoms (vaginal discharge) and difficulties in sexual functioning (Day, 2001; Day et al, 2001). The final analysis of the effects of AIs on the quality of life is still pending, but there are preliminary evidences that anastrozole may cause a decline in sexual functioning compared to tamoxifen (Fallowfield et al, 2002). While the ATAC trial showed that postmenopausal symptoms such as hot flushes are fewer with anastrozole, this is arguably offset by the higher prevalence of musculoskeletal complaints, which may be quite marked in some patients (Sainsbury, 2002).

\section{Cost}

Aromatase inhibitors cost several fold more than tamoxifen, a critical issue for seniors without a prescription drug benefit or in the context of government-run health-care systems. From a pharmacoeconomics perspective, using a decision model (Markov process) based on the UK National Health Service, letrozole is a cost-effective alternative first-line therapy, compared with tamoxifen for postmenopausal women with advanced breast cancer, achieving additional life-years at a mean incremental cost per lifeyear gain of $£ 2342$ (Karnon and Jones, 2003). In another costeffectiveness analysis undertaken in Canada using a decision model, quality-adjusted progression-free survivals between letrozole and anastrozole were comparable. Letrozole and anastrozole cost Can $\$ 2883$ and Can $\$ 2847$ per patient, respectively, which were marginally higher than tamoxifen at Can $\$ 2258$ per patient. This translated into an incremental cost over tamoxifen per qualityadjusted progression-free year of $\$ 12,500$ for letrozole and $\$ 19600$ for anastrozole (Dranitsaris et al, 2003).

\section{Conclusion and future directions}

The third-generation AIs are a welcome additional option for the endocrine therapy of hormone receptor-positive breast cancer in postmenopausal women. While nonsteroidal AIs are more effective than tamoxifen for the treatment of advanced disease, the absolute reduction in relapse-free survival for adjuvant AIs over tamoxifen is modest, and the results of several other large adjuvant trials are currently pending. Since there is currently no evidence that the use of an AI increases the number of patients cured of their disease, we consider the impact of AI therapy to be relatively modest, at least for the moment. The efficacy differences between tamoxifen and an AI are likely to remain fairly narrow, because ultimately these agents target the same signal transduction pathway. A critical focus is, therefore, to develop and translate insights into the molecular basis for endocrine therapy resistance. Neoadjuvant studies are proving part of the key, since tissue is readily available for genomic and proteomic approaches. Efforts should now also be made to profile samples from advanced disease, in order to fully understand the nature of the problem, since acquired resistance is not adequately addressed in neoadjuvant studies. Combining AIs and antioestrogens with a second signal transduction inhibitor to prevent or even reverse endocrine therapy resistance is now under investigation. The number of studies is rapidly expanding, and involve a spectrum of agents including COX2 inhibitors (Harris 
et al, 2000), HER1 and HER2 kinase inhibitors (Kurokawa and Arteaga, 2001), farnesyl transferase inhibitors (Johnston et al, 2003) and mTOR inhibitors (Mita et al, 2003). Combining

\section{REFERENCES}

ATAC (2002) Anastrozole alone or in combination with tamoxifen versus tamoxifen alone for adjuvant treatment of postmenopausal women with early breast cancer: first results of the ATAC randomised trial. Lancet 359: $2131-2139$

Bonneterre J, Buzdar A, Nabholtz JM, Robertson JF, Thurlimann B, von Euler M, Sahmoud T, Webster A, Steinberg M (2001) Anastrozole is superior to tamoxifen as first-line therapy in hormone receptor positive advanced breast carcinoma. Cancer 92: 2247-2258

Bonneterre J, Thurlimann B, Robertson JF, Krzakowski M, Mauriac L, Koralewski P, Vergote I, Webster A, Steinberg M, von Euler M (2000) Anastrozole versus tamoxifen as first-line therapy for advanced breast cancer in 668 postmenopausal women: results of the Tamoxifen or Arimidex Randomized Group Efficacy and Tolerability study. J Clin Oncol 18: $3748-3757$

Brodie A, Jelovac D, Long BJ (2003) Predictions from a preclinical model: studies of aromatase inhibitors and antiestrogens. Clin Cancer Res 9: $455 \mathrm{~S}-459 \mathrm{~S}$

Buzdar A (2002) The ATAC ('Arimidex', Tamoxifen, Alone or in Combination) trial in postmenopausal women with early breast cancer - updated efficacy results based on a median follow-up of 47 months (abstract 13). San Antonio Breast Cancer Symposium, San Antonio, Texas, USA

Coombes C, Bliss J, Hall E, Gibson L, Fallowfield L, Massimini G (2003) Under-reporting of symptoms in patients with early breast cancer (EBC) who have received tamoxifen treatment for $2-3$ years (abstract 48 ). Proc Am Soc Clin Oncol 22: 13

Day R (2001) Quality of life and tamoxifen in a breast cancer prevention trial: a summary of findings from the NSABP P-1 study. National Surgical Adjuvant Breast and Bowel Project. Ann N Y Acad Sci 949: $143-150$

Day R, Ganz PA, Costantino JP (2001) Tamoxifen and depression: more evidence from the National Surgical Adjuvant Breast and Bowel Project's Breast Cancer Prevention (P-1) Randomized Study. J Natl Cancer Inst 93: $1615-1623$

Dirix L, Piccart M, Lohrisch C, Beex L, Nooij M, Cameron D, Biganzoli L, Cufer T, Yague C, Duchateau L, Lobelle JP, Paridaens R (2001) Efficacy of and tolerance to exemestane (E) versus tamoxifen (T) in 1st line hormone therapy (HT) of postmenopausal metastatic breast cancer (MBC) patients (pts): a European Organisation for the Research and Treatment of Cancer (EORTC Breast Group) Phase II trial with Pharmacia and Upjohn (abstract 114). Proc Am Soc Clin Oncol 20: 29a

Dranitsaris G, Verma S, Trudeau M (2003) Cost utility analysis of first-line hormonal therapy in advanced breast cancer: comparison of two aromatase inhibitors to tamoxifen. Am J Clin Oncol 26: 289-296

Eiermann W, Paepke S, Appfelstaedt J, Llombart-Cussac A, Eremin J, Vinholes J, Mauriac L, Ellis M, Lassus M, Chaudri-Ross HA, Dugan M, Borgs M (2001) Preoperative treatment of postmenopausal breast cancer patients with letrozole: a randomized double-blind multicenter study. Ann Oncol 12: $1527-1532$

Elisaf MS, Bairaktari ET, Nicolaides C, Kakaidi B, Tzallas CS, Katsaraki A, Pavlidis NA (2001) Effect of letrozole on the lipid profile in postmenopausal women with breast cancer. Eur J Cancer 37: 1510-1513

Ellis MJ, Coop A, Singh B, Mauriac L, Llombert-Cussac A, Janicke F, Miller WR, Evans DB, Dugan M, Brady C, Quebe-Fehling E, Borgs M (2001) Letrozole is more effective neoadjuvant endocrine therapy than tamoxifen for ErbB-1- and/or ErbB-2-positive, estrogen receptor-positive primary breast cancer: evidence from a phase III randomized trial. J Clin Oncol 19: $3808-3816$

Ellis MJ, Coop A, Singh B, Mauriac L, Llombert-Cussac A, Janicke F, Miller WR, Evans DB, Dugan M, Brady C, Quebe-Fehling E, Borgs M (2003) Letrozole inhibits tumor proliferation more effectively than tamoxifen independent of HER1/2 expression status. Cancer Res 63: $6523-6531$

Fallowfield LJ, Leaity SK, Howell A, Benson S, Cella D (1999) Assessment of quality of life in women undergoing hormonal therapy for breast cancer: validation of an endocrine symptom subscale for the FACT-B. Breast Cancer Res Treat 55: 189-199 endocrine therapy with the rational use of these agents may be our best hope for more dramatic advances in the treatment of this common disease.
Fallowfield LJ, Cella D (2002) Assessing the quality of life (QOL) of post menopausal (PM) women randomized into the ATAC ('Arimidex', 'Tamixifen' alone or in combination) adjuvant breast cancer trial (Abstract 159) (2002). Proc Am Soc Clin Oncol 21: 40a

Goldhirsch A, Wood WC, Gelber RD, Coates AS, Thurlimann B, Senn HJ (2003) Meeting highlights: updated International Expert Consensus on the primary therapy of early breast cancer. J Clin Oncol 21: 3357-3365

Gottardis MM, Jordan VC (1988) Development of tamoxifen-stimulated growth of MCF-7 tumors in athymic mice after long-term antiestrogen administration. Cancer Res 48: $5183-5187$

Harris RE, Alshafie GA, Abou-Issa H, Seibert K (2000) Chemoprevention of breast cancer in rats by celecoxib, a cyclooxygenase 2 inhibitor. Cancer Res 60: $2101-2103$

Hays J, Ockene JK, Brunner RL, Kotchen JM, Manson JE, Patterson RE, Aragaki AK, Shumaker SA, Brzyski RG, LaCroix AZ, Granek IA, Valanis BG (2003) Effects of estrogen plus progestin on health-related quality of life. N Engl J Med 348: 1839-1854

Howell A (2000) Faslodex (ICI 182780). An oestrogen receptor downregulator. Eur J Cancer 36(Suppl 4): S87-S88

Ingle JN (2002) Estrogen as therapy for breast cancer. Breast Cancer Res 4: $133-136$

Irish W, Sherrill E, Gard C, Cole B (2002) Quality-adjusted survival of letrozole versus tamoxifen in post-menopausal women with advanced breast cancer (abstract 258). San Antonio Breast Cancer Symposium, San Antonio, Texas, USA

Johnston SR, Hickish T, Ellis P, Houston S, Kelland L, Dowsett M, Salter J, Michiels B, Perez-Ruixo JJ, Palmer P, Howes A (2003) Phase II study of the efficacy and tolerability of two dosing regimens of the farnesyl transferase inhibitor, R115777, in advanced breast cancer. J Clin Oncol 21: $2492-2499$

Karnon J, Jones T (2003) A stochastic economic evaluation of letrozole versus tamoxifen as a first-line hormonal therapy: for advanced breast cancer in postmenopausal patients. Pharmacoeconomics 21: $513-525$

Kurokawa H, Arteaga CL (2001) Inhibition of erbB receptor (HER) tyrosine kinases as a strategy to abrogate antiestrogen resistance in human breast cancer. Clin Cancer Res 7: 4436s-4442s (discussion 4411s-4412s)

Lonning PE, Bajetta E, Murray R, Tubiana-Hulin M, Eisenberg PD, Mickiewicz E, Celio L, Pitt P, Mita M, Aaronson NK, Fowst C, Arkhipov A, di Salle E, Polli A, Massimini G (2000) Activity of exemestane in metastatic breast cancer after failure of nonsteroidal aromatase inhibitors: a phase II trial. J Clin Oncol 18: 2234-2244

Makris A, Thomas R, Bloomfield D, Godward S, Moody M (2002) Examining the tolerability, quality of life and patient preference of letrozole versus anastrozole in a multicentre, randomised, single blind cross over study (abstract 265). San Antonio Breast Cancer Symposium, San Antonio, Texas, USA

McEwen BS, Alves SE, Bulloch K, Weiland NG (1997) Ovarian steroids and the brain: implications for cognition and aging. Neurology 48: S8-S15

Miller WR (1991) Aromatase activity in breast tissue. J Steroid Biochem Mol Biol 39: $783-790$

Mita MM, Mita A, Rowinsky EK (2003) Mammalian target of rapamycin: a new molecular target for breast cancer. Clin Breast Cancer 4: 126-137

Mouridsen H, Gershanovich M, Sun Y, Perez-Carrion R, Boni C, Monnier A, Apffelstaedt J, Smith R, Sleeboom HP, Jaenicke F, Pluzanska A, Dank M, Becquart D, Bapsy PP, Salminen E, Snyder R, Chaudri-Ross H, Lang R, Wyld P, Bhatnagar A (2003) Phase III study of letrozole versus tamoxifen as first-line therapy of advanced breast cancer in postmenopausal women: analysis of survival and update of efficacy from the International Letrozole Breast Cancer Group. J Clin Oncol 21: 2101-2109

Mouridsen H, Gershanovich M, Sun Y, Perez-Carrion R, Boni C, Monnier A, Apffelstaedt J, Smith R, Sleeboom HP, Janicke F, Pluzanska A, Dank M, Becquart D, Bapsy PP, Salminen E, Snyder R, Lassus M, Verbeek JA, Staffler B, Chaudri-Ross HA, Dugan M (2001) Superior efficacy of letrozole versus tamoxifen as first-line therapy for postmenopausal women with advanced breast cancer: results of a phase III study of the International Letrozole Breast Cancer Group. J Clin Oncol 19: $2596-2606$ 
Nabholtz JM, Buzdar A, Pollak M, Harwin W, Burton G, Mangalik A, Steinberg M, Webster A, von Euler M (2000) Anastrozole is superior to tamoxifen as first-line therapy for advanced breast cancer in postmenopausal women: results of a North American multicenter randomized trial. Arimidex Study Group. J Clin Oncol 18: 3758-3767

Paganini-Hill A, Clark LJ (2000) Preliminary assessment of cognitive function in breast cancer patients treated with tamoxifen. Breast Cancer Res Treat 64: $165-176$

Rossouw JE, Anderson GL, Prentice RL, LaCroix AZ, Kooperberg C, Stefanick ML, Jackson RD, Beresford SA, Howard BV, Johnson KC, Kotchen JM, Ockene J (2002) Risks and benefits of estrogen plus progestin in healthy postmenopausal women: principal results From the Women's Health Initiative randomized controlled trial. JAMA 288: $321-333$

Sainsbury, on behalf of the ATAC Trialists' \& Group (2002) Beneficial sideeffect profile of anastrozole compared with tamoxifen confirmed by additional 7 months of exposure data: a safety update from the 'Arimidex', Tamoxifen, Alone or in Combination (ATAC) trial (abstract 633). San Antonio Breast Cancer Symposium, San Antonio, Texas, USA

Santen RJ, Song RX, Zhang Z, Kumar R, Jeng MH, Masamura S, Yue W, Berstein L (2003) Adaptive hypersensitivity to estrogen: mechanism for superiority of aromatase inhibitors over selective estrogen receptor modulators for breast cancer treatment and prevention. Endocr Relat Cancer 10: $111-130$

Smith IE, Dowsett M (2003) Aromatase inhibitors in breast cancer. N Engl J Med 348: $2431-2442$

Song RX, Mor G, Naftolin F, McPherson RA, Song J, Zhang Z, Yue W, Wang J, Santen RJ (2001) Effect of long-term estrogen deprivation on apoptotic responses of breast cancer cells to 17beta-estradiol. J Natl Cancer Inst 93: 1714-1723

Thurlimann B, Beretta K, Bacchi M, Castiglione-Gertsch M, Goldhirsch A, Jungi WF, Cavalli F, Senn HJ, Fey M, Lohnert T (1996) First-line fadrozole HCI (CGS 16949A) versus tamoxifen in postmenopausal women with advanced breast cancer. Prospective randomised trial of the Swiss Group for Clinical Cancer Research SAKK 20/88. Ann Oncol 7: $471-479$

Tominaga T, Adachi I, Sasaki Y, Tabei T, Ikeda T, Takatsuka Y, Toi M, Suwa T, Ohashi Y (2003) Double-blind randomised trial comparing the non-steroidal aromatase inhibitors letrozole and fadrozole in postmenopausal women with advanced breast cancer. Ann Oncol 14: $62-70$

Winer EP, Hudis C, Burstein HJ, Bryant J, Chlebowski RT, Ingle JN, Edge SB, Mamounas EP, Gelber R, Gralow J, Goldstein LJ, Pritchard KI, Braun S, Cobleigh MA, Langer AS, Perotti J, Powles TJ, Whelan TJ, Browman GP (2003) American Society of Clinical Oncology technology assessment working group update: use of aromatase inhibitors in the adjuvant setting. J Clin Oncol 21: 2597-2599

Winer EP, Hudis C, Burstein HJ, Chlebowski RT, Ingle JN, Edge SB, Mamounas EP, Gralow J, Goldstein LJ, Pritchard KI, Braun S, Cobleigh MA, Langer AS, Perotti J, Powles TJ, Whelan TJ, Browman GP (2002) American Society of Clinical Oncology technology assessment on the use of aromatase inhibitors as adjuvant therapy for women with hormone receptor-positive breast cancer: status report 2002. J Clin Oncol 20: $3317-3327$

Wong ZW, Ellis MJ (2003) Neoadjuvant endocrine therapy for breast cancer: an overlooked option in the United States. Oncology (Huntingt), (in press) 